\title{
An Implementation of Compact Quarter-Wave-Like- Transformers Using Multi-Section Transmission Lines
}

\author{
Thanatcha SATITCHANTRAKUL ${ }^{1}$, Nonchanutt CHUDPOOTI ${ }^{2}$, Prayoot AKKARAEKTHALIN ${ }^{2}$, \\ Rardchawadee SILAPUNT ${ }^{1}$, Danai TORRUNGRUENG ${ }^{3}$ \\ ${ }^{1}$ Dept. of Electronic and Telecommunication Engineering, King Mongkut's University of Technology Thonburi, \\ 126 Pracha Uthit Rd., Bang Mod, Thung Khru, Bangkok, Thailand \\ ${ }^{2}$ Dept. of Electrical and Computer Engineering, King Mongkut's University of Technology North Bangkok, \\ 1518 Pracharat 1 Rd., Wongsawang, Bangsue, Bangkok, Thailand \\ ${ }^{3}$ Dept. of Electrical and Electronic Engineering, Asian University, Huay yai, Banglamung, Chonburi, Thailand
}

\{thanatcha.sat, rardchawadee.sil\}@mail.kmutt.ac.th, c.nonchanutt@gmail.com, prayoot@kmutnb.ac.th, danait@asianu.ac.th

Submitted July 30, 2017 / Accepted November 22, 2017

\begin{abstract}
This paper proposes a novel miniaturization technique of quarter-wave transformers (QWTs), implemented using multi-section transmission lines (MSTLs), based on the quarter-wave-like transformer ( $Q W L T)$ theory. Multi-section QWLT characteristics are derived analytically and solved via appropriate optimization algorithms for associated transmission-line parameters. For an illustration purpose, two- and three-section QWLT prototypes with $50 \%$ physical size reduction from the corresponding QWT size operating at $2.4 \mathrm{GHz}$ are fabricated using microstrips and tested. It is found that these prototypes yield acceptable return loss at $2.4 \mathrm{GHz}$ without significant bandwidth reduction, comparing to the QWT result.
\end{abstract}

\section{Keywords}

Quarter-wave transformer, quarter-wave-like transformer, multi-section transmission line

\section{Introduction}

Microwave devices such as amplifiers, directional couplers, power dividers, filters, and antennas are common integrated components of modern electronic circuits and communication systems. The physical dimension of microwave devices strongly depends on the operating frequency. As the world is moving into the digital era, sizes of electronic and communication components are significantly reduced to incorporate more features but yet maintain high performance. The challenges on size reduction, especially at low microwave frequency, thus have attracted many researchers in last few decades. Various techniques have been proposed to obtain high performance compact devices [1-27].
One of the miniaturization techniques is to load transmission lines (TLs) with appropriate lumped components or TL stubs to slow the wave propagation, which are known as slow-wave structures [1-3]. This technique offers a significant size reduction and easy integration to integrated circuits (ICs). However, it still suffers from low quality factor and high power losses. Another approach is the low-temperature co-fired ceramic (LTCC) technology [4], [5]. The multilayer sections of ceramic substrates with conductive layers provide a compact size, high conductivity, and lower surface roughness. However, these LTCC structures still suffer from loss dissipated into the composite metal materials. In addition, the method based on metamaterials is another interesting approach, where associated artificial TLs possess tiny unit cells. The electromagnetic properties of metamaterials can be controlled and designed by using left- or composite right/left- handed (CRLH) concept [6-8]. However, associated structures are rather complex, thus not easy to design and also need to take care of the coupling effect between elements.

Based on slow-wave structures, another approach of miniaturizing microwave components is the technique of electromagnetic bandgap (EBG) structures. These structures can form passband and stopband characteristics to slow the wave propagation as well, where they can be fabricated on an underlying substrate, etched in a TL, or formed as a ground plane [9-11]. However, their lattice design especially in three-dimensional structures is rather complicated since it requires an integration of many unit cells. Furthermore, slow-wave structures, formed by substrate integrated waveguides (SIWs), have also been proposed [12-15]. The additional metal layer over the ground plane improves the signal carrying efficiency. However, the complexity and the cost of fabrication are still an issue. Recently, another slow-wave structure is based on compact microstrip resonant cells (CMRCs) [16-18]. Their slowwave characteristic in passband regions is a result of suffi- 
cient discontinuity in structures. They thus offer more flexibility in geometry design, but it is limited only on symmetric cells.

The technique of multi-section TLs (MSTLs) stands out as another interesting approach for device miniaturization [19-24]. It provides acceptable performance comparing with other techniques, yet with simple design and fabrication. Moreover, associated unit cells can be designed as symmetric or asymmetric structures, leading to more flexible dimension. One of good examples of MSTLs is in [21], where arbitrary lengths of MSTLs are proposed with good impedance matching and greater section lengths. Another example is the constant voltage-standing wave ratio (VSWR)-type TL impedance transformers (CVTs) and constant conductance-type TL impedance transformers (CCTs) [22-24]. They are proved to have a wide bandwidth with a great reduction size designing based on the close form equations. Recently, a new type of MSTLs has been proposed [25]. This work attempts to miniaturize quarter wave transformers (QWTs) using conjugately characteristic-impedance TLs (CCITLs) [26-28], known as quarter-wave-like transformers (QWLTs). The strengths of QWLTs over the standard QWT are their ability to support the slow-wave propagation associated with multi-section asymmetric unit cells and to reduce the total physical length of associated TLs based on the QWLT theory.

The purpose of this paper is to illustrate the implementation of compact multi-section QWLTs and to study their characteristics. Analytical formulas of multi-section QWLTs are first derived based on the $A B C D$ matrix of associated unit cells. Note that this approach is more general, flexible and also includes the design method of the CVT/CCT as a special case. For illustration, two- and three-section QWLTs with $25 \%$ and $50 \%$ physical size reduction are designed and simulated at $2.4 \mathrm{GHz}$. In addition, the implementation of $50 \%$ physical size reduction of two- and three-section QWLT prototypes is then performed. Their characteristics are compared with those of the standard QWT. It is found that asymmetric multi-sections provide more flexibility in the design. It should be pointed out that the unique advantage of this QWLT approach over other techniques based on slow-wave structures for compact impedance transformers is that the total electrical length of QWLTs can be reduced to $\lambda / q$, with $q>4$. However, for other slow-wave structures, their size reduction capability always has the quarter-wave $(\lambda / 4)$ limitation, where $\lambda$ is the effective wavelength associated with slow-wave structures at the operating frequency of interest.

This paper is organized as follows. Section 2 demonstrates the theoretical formulation based on the theory of QWLTs, including multi-section QWLT characteristics. Examples of the QWLT design and implementation for two- and three-section QWLTs are presented in Sec. 3, followed by results and discussions in Sec. 4. Finally, conclusions are given in Sec. 5.

\section{Theoretical Formulation}

In this section, the QWLT theory is briefly explained. Then, multi-section QWLT characteristics are studied analytically. Only reciprocal and lossless QWLTs are considered in the theoretical development.

Recently, it has been first demonstrated in [25] that applying CCITLs to the standard QWT can significantly reduce its physical dimension, where the new impedance matching component is called QWLTs as shown in Fig. 1. In [25], it is found that the magnitude of the characteristic impedances $Z_{c}^{ \pm}$and the electrical length $\theta_{c}$ of QWLTs of physical length $l$ can be expressed respectively as follows:

$$
\begin{aligned}
& \left|Z_{c}^{ \pm}\right|=\sqrt{Z_{0} Z_{L}}, \\
& \theta_{c}=\beta l \\
& =\left\{\begin{array}{lll}
\tan ^{-1}\left(-\Gamma_{f, L} \cot (\phi)\right) & \text { when } & Z_{L}>Z_{0} \text { and } \phi<0 \\
& & Z_{L}<Z_{0} \text { and } \phi>0 \\
\tan ^{-1}\left(-\Gamma_{f, L} \cot (\phi)\right)+\pi & \text { when } & Z_{L}>Z_{0} \text { and } \phi>0 \\
& Z_{L}<Z_{0} \text { and } \phi<0
\end{array} .\right.
\end{aligned}
$$

where the argument $\phi$ of $Z_{r, c}$ is in the range of $-90^{\circ} \leq \phi \leq 90^{\circ}, \beta$ is the effective propagation constant of QWLTs, $Z_{0}$ is the feedline impedance, $Z_{\mathrm{L}}$ is the load impedance, and the reflection coefficient $\Gamma_{\mathrm{f}, \mathrm{L}}$ is defined as

$$
\Gamma_{\mathrm{f}, \mathrm{L}}=\frac{Z_{\mathrm{L}}-Z_{0}}{Z_{\mathrm{L}}+Z_{0}} .
$$

Note that $Z_{0}$ and $Z_{\mathrm{L}}$ are real and given for a specific impedance-matching problem.

In Fig. $1, Z_{\text {in }}$ is the input impedance of the terminated QWLT. To match the lossless feedline, $Z_{\text {in }}$ must be real and equal to $Z_{0}$, which can be readily obtained using (1) and (2). It should be pointed out that the argument $\phi$ must be chosen properly to obtain less electrical and physical lengths of QWLTs, compared to those of corresponding QWTs, as discussed in detail in [25].

Consider the $A B C D$ matrix of the reciprocal QWLT in Fig. 1. In [26], it is shown that $Z_{c}^{ \pm}$and $\theta_{c}$ can be determined from its $A B C D$ parameters as follows:

$$
\begin{gathered}
Z_{c}^{ \pm}=\frac{\mp 2 B}{A-D \mp \mathrm{j} \sqrt{4-(A-D)^{2}}}, \\
\cos \theta_{c}=\frac{A+D}{2} .
\end{gathered}
$$

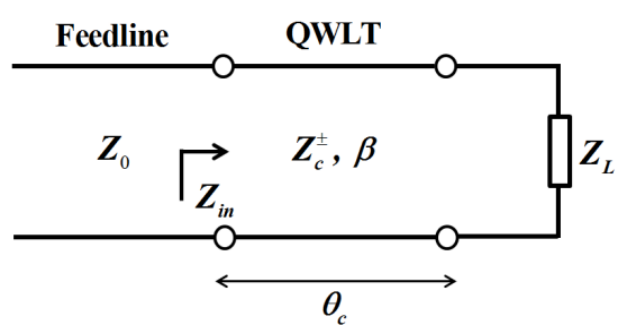

Fig. 1. A QWLT impedance matching circuit [25]. 
Thus, it is required to determine the $A B C D$ parameters to satisfy (1) and (2) simultaneously to obtain desired QWLTs, which is quite complicated and usually requires an optimization algorithm. Once the $A B C D$ parameters are found, desired QWLTs can be implemented using MSTLs by determining corresponding TL parameters of MSTLs.

To simplify the above optimization problem, let us reconsider the $A B C D$ matrix of the QWLT in Fig. 1. It can be readily shown that $Z_{\text {in }}$ and $Z_{\mathrm{L}}$ are related to the $A B C D$ parameters via the following relationship:

$$
Z_{\text {in }}=\frac{A Z_{\mathrm{L}}+B}{C Z_{\mathrm{L}}+D}
$$

Using (6) with the fact that the QWLT is reciprocal $(A D-B C=1)$ and $Z_{\text {in }}$ is real, one obtains two simple relationships as follows:

$$
\begin{aligned}
& \frac{A}{D}=\frac{Z_{\text {in }}}{Z_{\mathrm{L}}}, \\
& \frac{B}{C}=Z_{\text {in }} Z_{\mathrm{L}} .
\end{aligned}
$$

Note that (7) and (8) are identical to those derived using the image parameter method [29]. It should be pointed out that the $A B C D$ parameters satisfying (7) and (8) automatically satisfy (1), (2), (4) and (5) as well since the original impedance-matching problem is the same. However, (7) and (8) look much simpler to solve for associated unknown parameters.

In this study, QWLTs are implemented using MSTLs. For illustration purpose, only two- and three-section TLs of a unit cell of length $l$ are considered to form QWLTs with characteristic impedances $Z_{c}^{ \pm}$and electrical length $\theta_{c}$ as shown in Fig. 2(a) and (b) respectively, where $Z_{n}$ is the characteristic impedance of the $n$th TL, $\theta_{n}=k_{n} l_{n}$ is its electrical length, $k_{n}$ is its propagation constant and $l_{n}$ is its physical length. In addition, it is assumed in this analysis that the propagation constants of each TL are identical $\left(k_{n}=k\right)$.

For the two-section QWLT in Fig. 2(a), the considered parameters are $Z_{1}, Z_{2}, l_{1}$ and $l_{2}$ where $l=l_{1}+l_{2}$ and $l$ is given for a specific impedance-matching problem. So, there are only 3 unknown parameters $\left(Z_{1}, Z_{2}\right.$ and $\left.l_{1}\right)$ to be considered for a given length $l$. For convenience in manipulation, the following parameters are defined:

$$
\begin{gathered}
r_{1}=\frac{Z_{\text {in }}}{Z_{\mathrm{L}}}, \\
r_{2}=Z_{\text {in }} Z_{\mathrm{L}} .
\end{gathered}
$$

Using (9) and (10) in (7) and (8) and the $A B C D$ matrix of two-section TLs [28], the characteristics of the twosection QWLT can thus be expressed in (11) and (12) as

$$
\tan \theta_{1} \tan \theta_{2}=\frac{1-r_{1}}{Z_{12}-\frac{r_{1}}{Z_{12}}},
$$

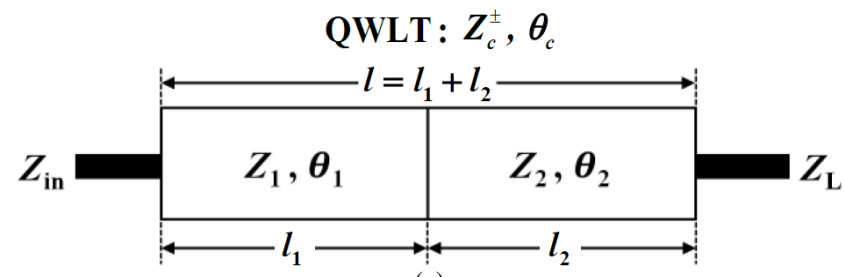

(a)

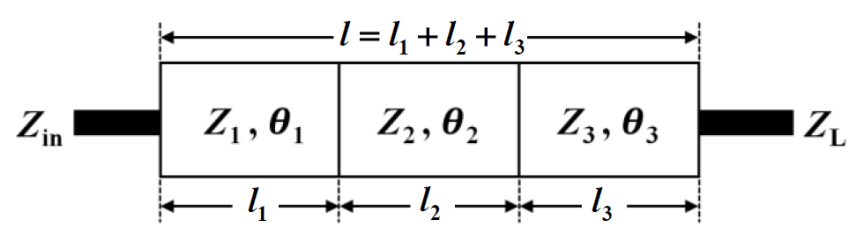

(b)

Fig. 2. A QWLT impedance matching circuit: (a) Two sections, (b) three sections.

$$
\tan \theta_{1} \cot \theta_{2}=Z_{12} \frac{r_{2}-Z_{2}^{2}}{Z_{1}^{2}-r_{2}}
$$

where $Z_{12}$ in (11) and (12) is defined as

$$
Z_{12}=\frac{Z_{1}}{Z_{2}}
$$

Thus, it is required to solve for $Z_{1}, Z_{2}$ and $l_{1}$ simultaneously using (11) and (12) with an optimization algorithm. Due to the fact that there are more numbers of unknowns than numbers of equations, two-section QWLTs are not unique for a given design problem as illustrated in Sec. 4.

For the three-section QWLT in Fig. 2(b), the considered parameters are $Z_{1}, Z_{2}, Z_{3}, l_{1}, l_{2}$ and $l_{3}$ where $l=l_{1}+l_{2}+l_{3}$ Similar to the case of two sections, five unknown parameters are considered only for a given length $l$ $\left(Z_{1}, Z_{2}, Z_{3}, l_{1}\right.$ and $\left.l_{2}\right)$. Similar to (11) and (12), the characteristics of the three-section QWLT can be written as (14) and (15):

$$
\begin{aligned}
\tan \theta_{1} \tan \theta_{2} \tan \theta_{3} & =\frac{1-r_{1}}{\cot \theta_{1}\left(\left(r_{1} / Z_{23}\right)-Z_{23}\right)} \\
& +\frac{1-r_{1}}{\cot \theta_{2}\left(\left(r_{1} / Z_{23}\right)-Z_{13}\right)} \\
& -\frac{1-r_{1}}{\cot \theta_{3}\left(\left(r_{1} / Z_{12}\right)-Z_{12}\right)}, \\
\tan \theta_{1} \tan \theta_{2} \tan \theta_{3}= & \frac{\tan \theta_{1}\left(Z_{1}-\left(r_{2} / Z_{1}\right)\right)}{Z_{12} Z_{3}-\left(r_{2} Z_{3} / Z_{12}\right)} \\
& +\frac{\tan \theta_{2}\left(Z_{2}-\left(r_{2}-Z_{2}\right)\right)}{Z_{12} Z_{3}-\left(r_{2} Z_{3} / Z_{12}\right)} \\
& -\frac{\tan \theta_{3}\left(\left(r_{2} / Z_{3}\right)-Z_{3}\right)}{Z_{12} Z_{3}-\left(r_{2} Z_{3} / Z_{12}\right)}
\end{aligned}
$$

where $Z_{13}$ and $Z_{23}$ are defined as

$$
Z_{13}=\frac{Z_{1}}{Z_{3}}
$$




$$
Z_{23}=\frac{Z_{2}}{Z_{3}}
$$

Thus, it is mandatory to solve for $Z_{1}, Z_{2}, Z_{3}, l_{1}$ and $l_{2}$ simultaneously using (14) and (15) with an optimization algorithm. Similar to the previous case, three-section QWLTs are not unique for a given design problem as well as illustrated in Sec. 4.

\section{Design and Implementation of QWLTs}

In this section, examples of QWLT design and implementation are discussed. Two case studies are multisection QWLTs with 25\% and 50\% physical size reduction compared to the corresponding QWT size. The operating frequency is at $2.4 \mathrm{GHz}$.

For illustration, QWLTs are designed using microstrips with the low loss substrate, called Arlon DiClad 880 (dielectric constant of $\varepsilon_{\mathrm{r}}=2.17$, loss tangent of $\tan \delta=0.0009$ and substrate height of $h=1.524 \mathrm{~mm}$ ). In this example, it is required to match a $100 \Omega$ load to a $50 \Omega$ input impedance. Using the Agilent Genesys EDA software [30], multi-section QWLTs implemented using microstrips are first simulated to obtain initial design parameters based on the minimum TL width of $0.2 \mathrm{~mm}$ on the substrate due to the limitation of the milling machine. Then, mutual coupling effects between TLs of multi-section QWLTs are taken into account using the finite integration technique (FIT) via the CST Microwave Studio (MWS) software [31]. After optimizing design parameters, optimized multi-section QWLTs are fabricated and then tested using a network analyzer.

The characteristic impedance $Z_{n}$ and associated length $l_{n}$ in Fig. 2(a) and (b) are determined via the Agilent Genesys EDA software using (11) and (12) or (14) and (15) for two or three sections, respectively. Since QWLTs are modified from the standard QWT, their length $l$ is then set to be equal to a quarter of wavelength multiplied by the reduction ratio $p$, that is $l=p \lambda / 4$ where $0<p \leq 1$. The ratio $p$ is equal to 1 for the standard QWT and equal to 0.75 and 0.5 for $25 \%$ and $50 \%$ physical size reduction, respectively. To observe the slow-wave characteristic of multi-section QWLTs, the slow-wave factor (SWF) is considered. In [11], the SWF is defined as the ratio of free space wavelength to guided wavelength or the ratio of the effective propagation constant $\beta$ of TLs of interest to the free space propagation constant $k$ where $\beta$ can be determined from (5) using $\theta_{c}=\beta l$ for QWLTs. Typically, higher SWF yields shorter associated TLs. In addition to the SWF, the modified SWF is also applied in this paper for fair comparisons, which is defined as the ratio of the effective propagation constant of QWLTs to the propagation constant of QWTs. Furthermore, the group delay is also considered as an important factor for evaluating TL quality [11]. Note that the voltage and current distributions along associated TLs are also determined to understand associated signal propagation characteristics better. These results will be provided in Sec. 4.

\section{Results and Discussions}

\subsection{QWLT-parameter Range Evaluation}

The Agilent Genesys EDA software is employed to determine the design parameters in Fig. 2(a) and (b), where the iteration numbers in the optimization algorithms, the gradient search and the pattern search, were set to 300 and 700 for two- and three-section QWLTs, respectively. As pointed out in Sec. 2, multi-section QWLTs are not unique for a given design problem. Tables 1 and 2 present the range of parameters of interest for ideal multi-section QWLTs with $25 \%$ and $50 \%$ physical size reduction, respectively.

From Tab. 1 and 2, it can be seen that all QWLT parameters vary with the required physical length and the number of TL sections of ideal QWLTs. Note that $\theta_{c}$ for a given $\phi$ agrees well with the QWLT theory in Sec. 2. It should be pointed out that $\theta_{c}$ is always less than $90^{\circ}$ (for the QWT) as expected. When the QWLT physical length decreases, $\theta_{c}$ tends to decrease and $\phi$ tends to increase. In addition, these QWLT matching networks provide a larger group delay caused by their dispersion [11], where the group delay of the corresponding ideal QWT is equal to 110.5 ps. Furthermore, the miniaturization capability can be further realized due to the SWF of greater than unity, where the SWF tends to increase when the QWLT physical length decreases. It can be observed that the three-section QWLT parameters tend to cover wider range than those of two-section QWLTs due to more degrees of freedom in the QWLT design.

\begin{tabular}{|c|c|c|c|c|}
\hline \multirow{2}{*}{ QWLT Parameter } & \multicolumn{2}{|c|}{ Two-section } & \multicolumn{2}{c|}{ Three-section } \\
\cline { 2 - 5 } & Min & Max & Min & Max \\
\hline $\begin{array}{c}\text { Electrical length } \theta_{c} \\
\left({ }^{\circ}\right)\end{array}$ & 68.89 & 71.49 & 67.8 & 76.87 \\
\hline Argument $|\phi|\left(^{\circ}\right)$ & 6.37 & 7.33 & 4.45 & 7.74 \\
\hline Group delay $(\mathrm{ps})$ & 179.3 & 183.1 & 176.5 & 202.9 \\
\hline SWF & 1.02 & 1.06 & 1.02 & 1.14 \\
\hline
\end{tabular}

Tab. 1. Range of QWLT parameters for ideal multi-section QWLTs with 25\% physical size reduction.

\begin{tabular}{|c|c|c|c|c|}
\hline \multirow{2}{*}{$\begin{array}{c}\text { QWLT } \\
\text { Parameter }\end{array}$} & \multicolumn{2}{|c|}{ Two-section } & \multicolumn{2}{c|}{ Three-section } \\
\cline { 2 - 5 } & Min & Max & Min & Max \\
\hline $\begin{array}{c}\text { Electrical length } \theta_{c} \\
\left({ }^{\circ}\right)\end{array}$ & 52.8 & 56.71 & 52.27 & 79.84 \\
\hline Argument $|\phi|\left(^{\circ}\right)$ & 12.35 & 14.19 & 3.54 & 14.46 \\
\hline Group delay (ps) & 149.2 & 160.6 & 147.7 & 225.4 \\
\hline SWF & 1.17 & 1.26 & 1.16 & 1.77 \\
\hline
\end{tabular}

Tab. 2. Range of QWLT parameters for ideal multi-section QWLTs with 50\% physical size reduction. 


\subsection{Simulation and Measurement Results}

From the above simulation results, multi-section QWLTs with 50\% physical size reduction are chosen as an example in the simulation of signal propagation characteristics. Both two- and three-section QWLTs are selected at the same SWF of 1.19 for a fair comparison as shown in Fig. 3. The ideal QWLTs in Fig. 3(a) and (b) are terminated in a $100 \Omega$ load and analyzed to determine their voltage and current distributions for a given input voltage and input impedance of $50 \Omega$. The corresponding ideal QWT is also analyzed for comparison, where its characteristic impedance is $70.7 \Omega$ and electrical length is $90^{\circ}$. The voltage and current distributions are determined using terminated lossless TL equations [28], where the input voltage $V_{\text {in }}$ is set at $1 \mathrm{~V}$. Numerical results of the magnitudes of voltage and current distributions shown in Fig. 4(a) and (b), respectively. Note that $V_{\text {in }}$ is located at the left end of twoand three-section QWLT as shown in Fig. 4(a). It is found that the distributions of both QWT and QWLTs exhibit similar trends, but different support, with equal voltage and current magnitudes at the input and load terminals. However, the QWLTs are significantly shorter and their voltage and current distributions are not smooth, with the slope discontinuity at associated TL junctions.

In addition, both SWF and modified SWF of ideal two- and three-section QWLTs in Fig. 3(a) and (b) are also considered as illustrated in Fig. 5. It can be seen that the SWF of ideal QWT is constant for all frequencies while those of ideal QWLTs slightly increase with frequency.
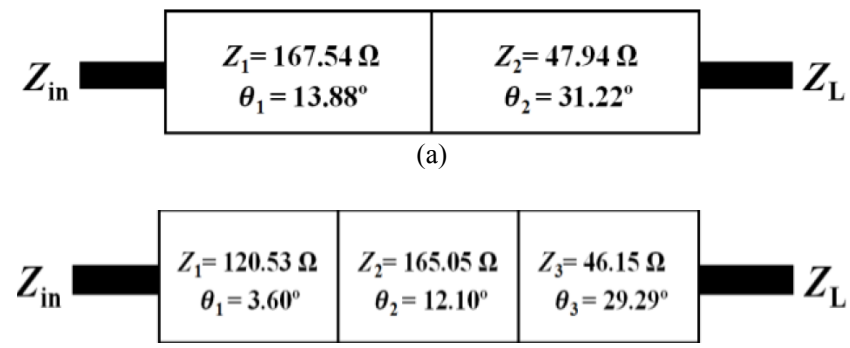

(b)

Fig. 3. Characteristic impedances and electrical lengths of QWLT unit cells: (a) Two sections, (b) three sections.

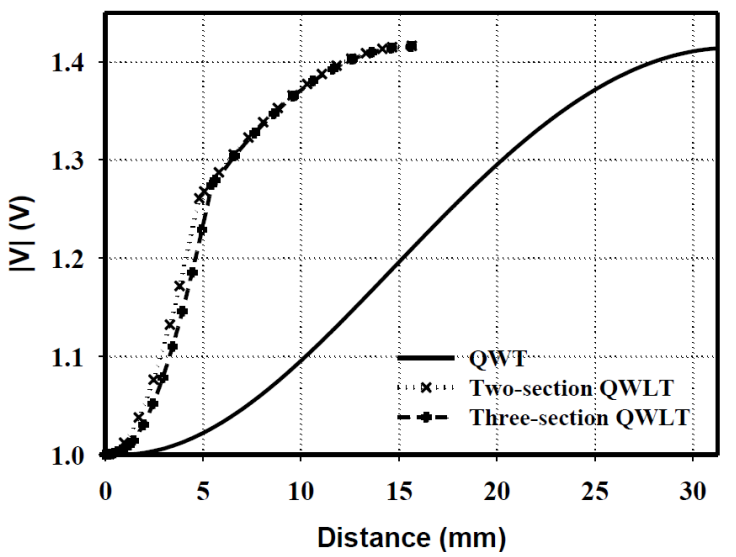

(a)

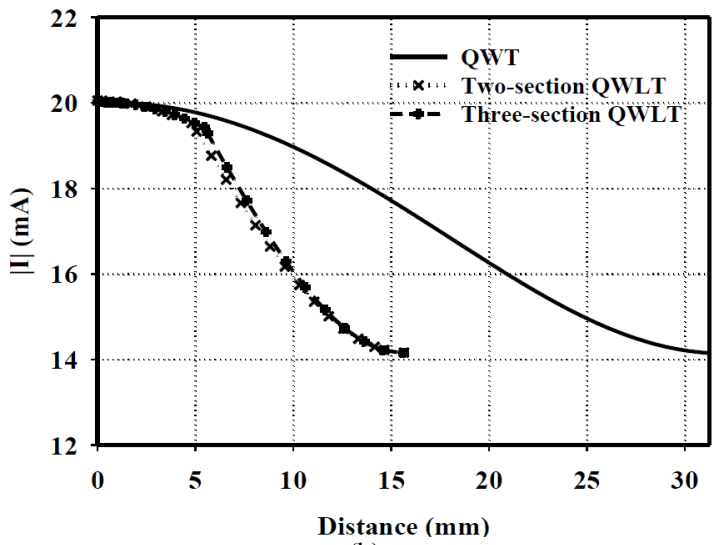

(b)

Fig. 4. The distributions of ideal QWT, two- and three- section QWLTs. (a) Magnitude of the voltage, (b) magnitude of the current.

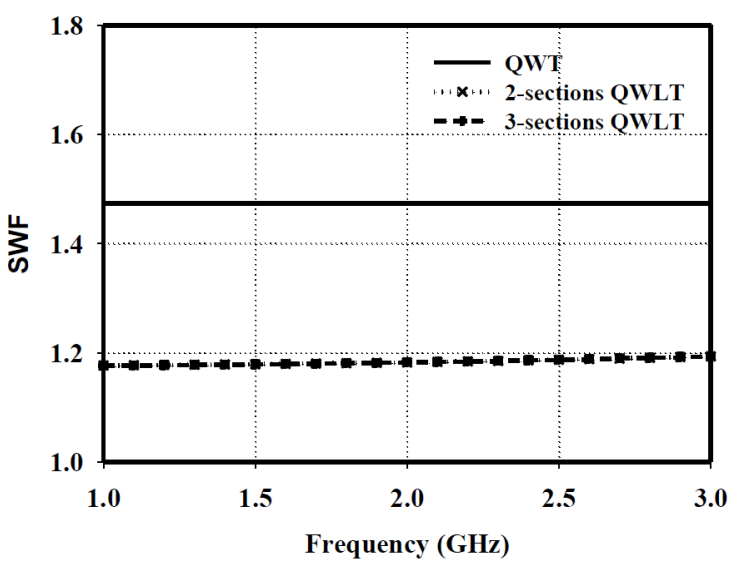

(a)

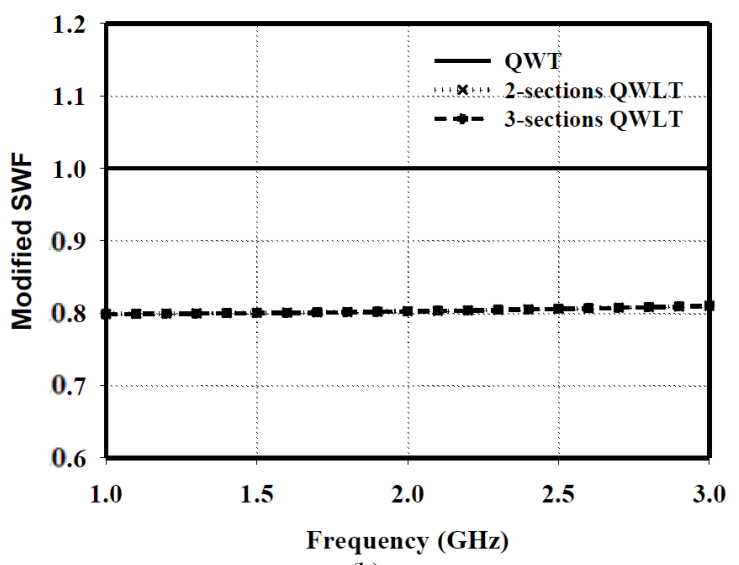

(b)

Fig. 5. Comparison of ideal QWT, two- and three-section QWLTs. (a) SWF, (b) modified SWF.

Note that the SWFs of both ideal two- and three-section QWLTs are almost identical and less than that of ideal QWT. Furthermore, the graph of modified SWF is plotted as shown in Fig. 5(b). It is found that the modified SWFs of ideal QWLTs slightly increase with frequency and are approximately equal to 0.8 . Although the modified SWFs are less than one, QWLTs with $50 \%$ physical size reduction can still be achieved in this case. 
Next, the two- and three- section QWLTs with characteristic impedances and electrical lengths in Fig. 3 are implemented using microstrips. The microstrip dimensions are further optimized by taking into account of mutual coupling effects using the CST MWS software. The final QWLT designs for prototype fabrication are illustrated in Fig. 6. Note that the total electrical lengths of both twoand three- section QWLTs are identical and reduced to $\lambda_{\text {QWLT }} / 6.04$, which are less than $\lambda_{\text {QWT }} / 4$ of the conventional QWT. $\lambda_{\text {QWLT }}$ and $\lambda_{\text {OWT }}$ are effective wavelengths associated with QWLTs and QWT respectively, and they are assumed to be the same for a fair comparison. For size comparison, the QWT is also implemented using the same microstrip with the width of $2.73 \mathrm{~mm}$ and length of $24.8 \mathrm{~mm}$. Figure 7(a), 7(b) and 7(c) depict the microstrip prototypes of QWT and two- and three-section QWLTs, respectively. In Figure 7(a), it illustrates the chip load resistor of $100 \Omega$ as

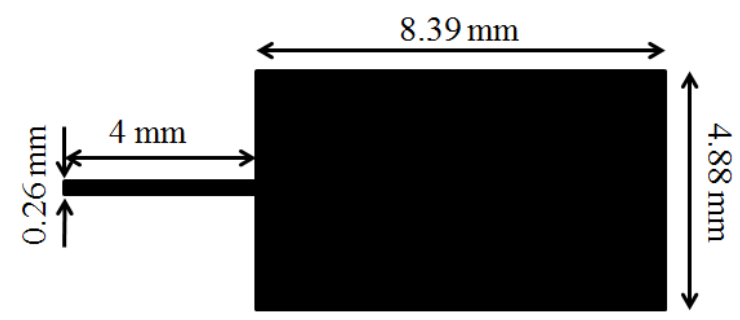

(a)

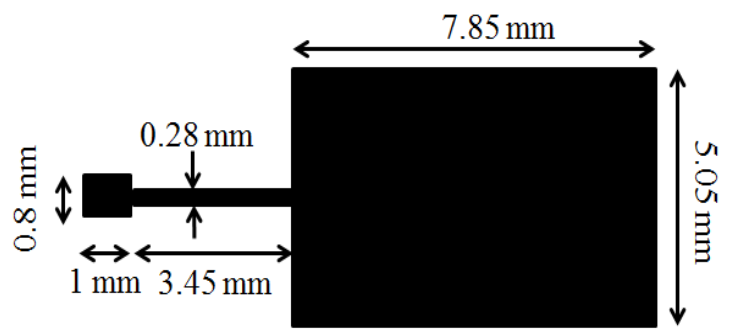

(b)

Fig. 6. Microstrip implementation of QWLT unit cells. (a) Two-section QWLT, (b) three-section QWLT.

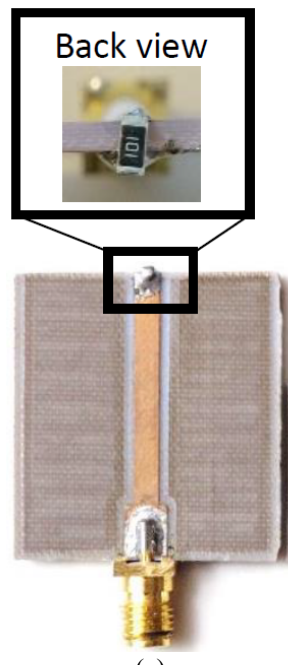

(a)

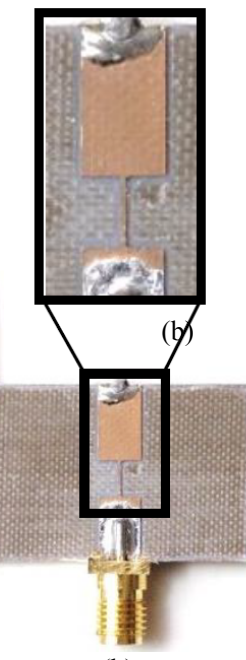

(b)

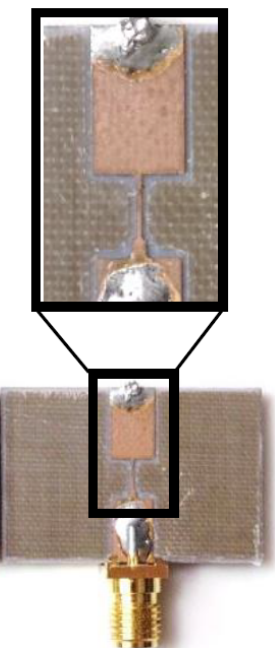

(c)
Fig. 7. QWT and QWLT microstrip prototypes. (a) QWT, two-section QWLT, (b) three-section QWLT. well. Note that all prototypes are fabricated on the finite substrate of $40 \mathrm{~mm}$ width. It is clearly seen that both QWLT prototypes are twice smaller in physical length than that of the QWT prototype (excluding the $50 \Omega$ input port).

Figure 8(a) shows the simulated and measured frequency responses of the magnitude of $S_{11}$ of the QWT microstrip prototype. In addition, similar results of twoand three-section QWLT microstrip prototypes are also illustrated in Fig. 8(b) and (c), respectively. It can be seen that measured results of $\left|S_{11}\right|$ of the QWLT prototypes agree reasonably well with simulated results.

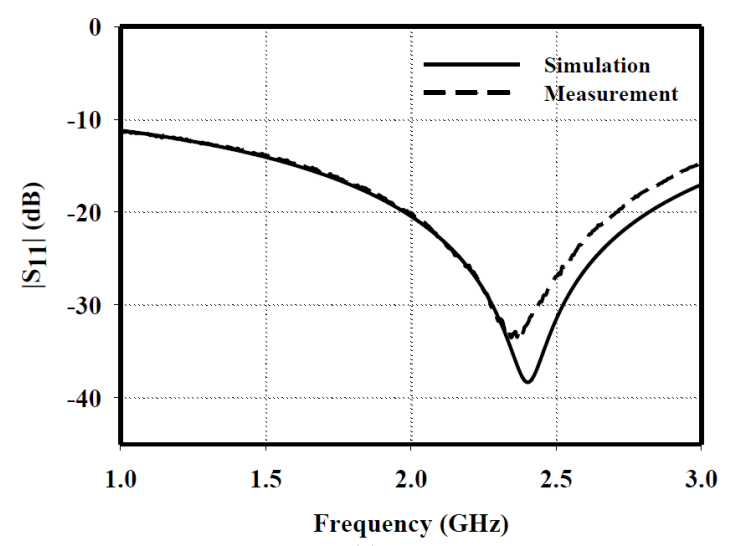

(a)

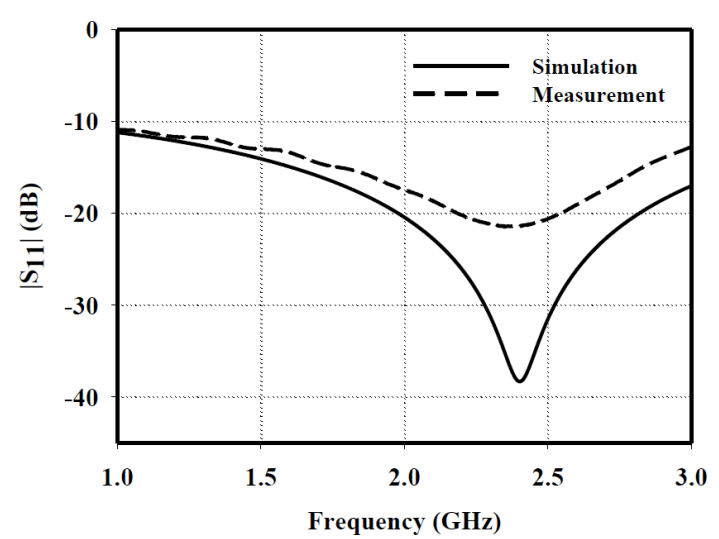

(b)

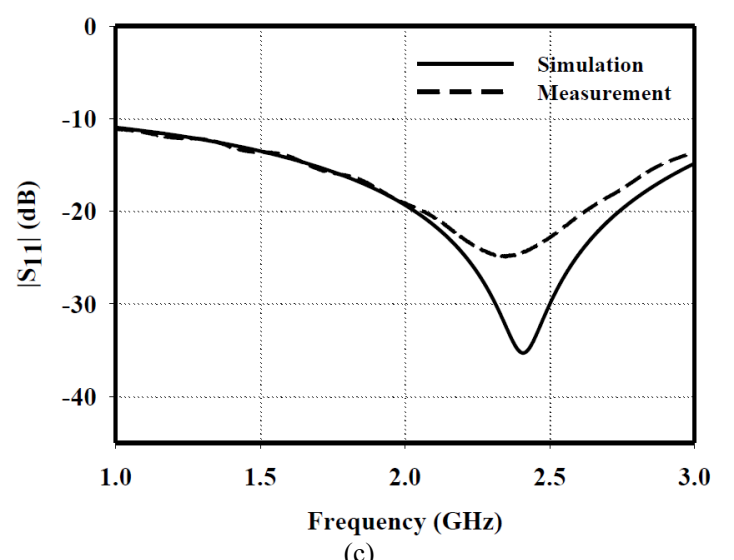

(c)

Fig. 8. Frequency response $\left|S_{11}\right|$ of transformers. (a) QWT, (b) Two-section QWLT, (c) Three-section QWLT. 


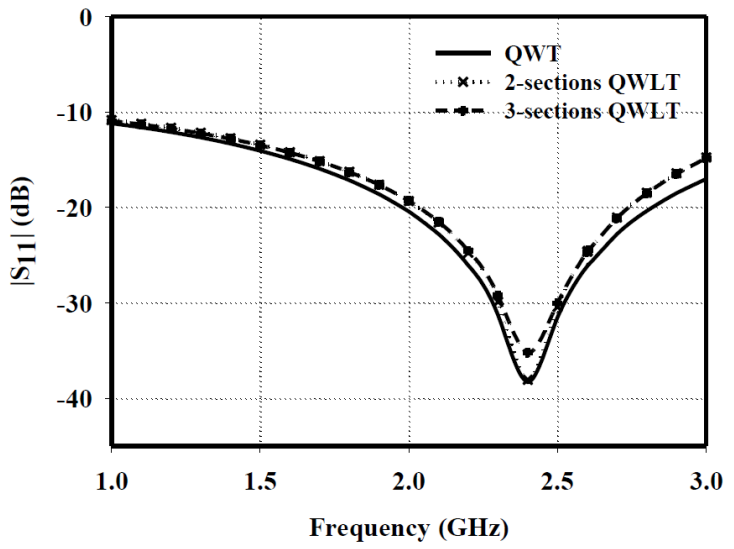

(a)

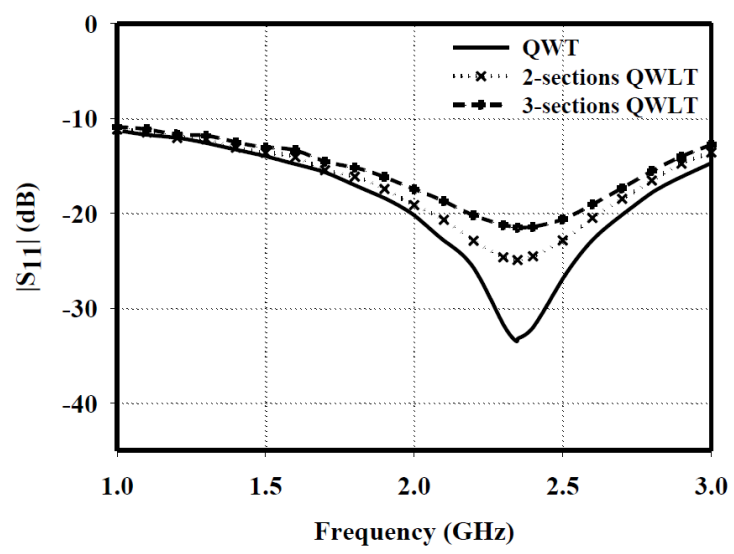

(b)

Fig. 9. Frequency response $\left|\mathrm{S}_{11}\right|$ of QWT and QWLT prototypes. (a) Simulation, (b) measurement.

In addition, Figure 9 illustrates different views of $\left|S_{11}\right|$ variations for better comparison, where simulated and measured results are shown separately in Fig. 9(a) and (b), respectively. Note that all frequency responses obtained from simulations are similar and less than $-30 \mathrm{~dB}$ at $2.4 \mathrm{GHz}$, where both $\left|\mathrm{S}_{11}\right|$ for QWLTs are slightly higher than that of the QWT. Note that their bandwidths of $\left|\mathrm{S}_{11}\right|$ at $\left|\mathrm{S}_{11}\right|=-20 \mathrm{~dB}$ are slightly less than that of the QWT. However, measured results of the QWLT prototypes exhibit higher $\left|\mathrm{S}_{11}\right|$, where they are still acceptable at $2.4 \mathrm{GHz}$, which are about $-22 \mathrm{~dB}$ and $-25 \mathrm{~dB}$ for two- and threesection QWLTs, respectively.

The two-section QWLT characteristics are compared with other methods as shown in Tab. 3. All these methods are compared using the same condition. Note that for QWLTs, (11) and (12) are used for calculation. It is clearly seen that all methods provide similar solutions, indicating the validity of the proposed method. Note that the QWLT approaches also offer general design equations of asymmetric MSTLs leading to more flexibility in design and implementation. The issue of high impedance line can be solved by adding more TL sections with proper impedance and electrical length. Moreover, this paper also presents additional details on multi-sections; i.e., voltage and current distribution and SWF. It is found that, for two-section QWLTs, if $\theta_{c}$ values are equal, then the bandwidths will be approximately equal. However, some differences are observed for higher number of TL sections.

It should be pointed out that QWLTs can also be designed using the characteristic impedance profiles. For example, Figure 10 shows the variation of $Z_{1}$ and $Z_{2}$ with $\theta_{1}$ for two-section QWLTs with 50\% size reduction, where $r_{1}$ is fixed at 0.5 and $\theta_{1}+\theta_{2}$ is approximately equal to $45^{\circ}$.

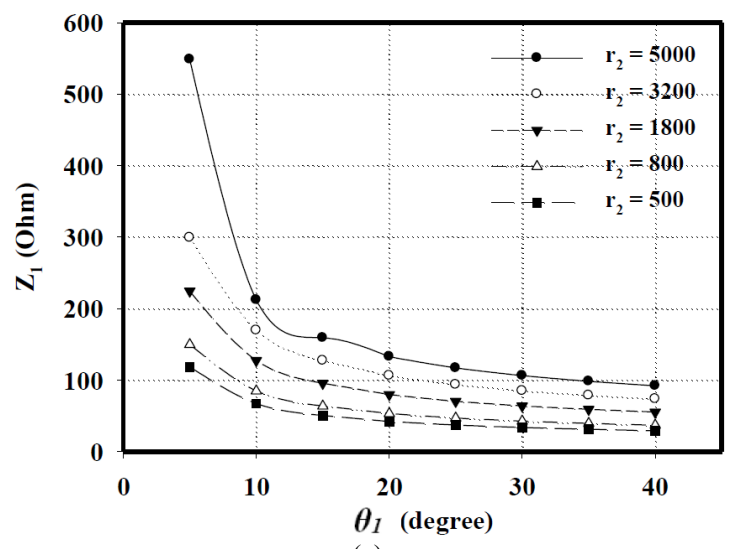

(a)

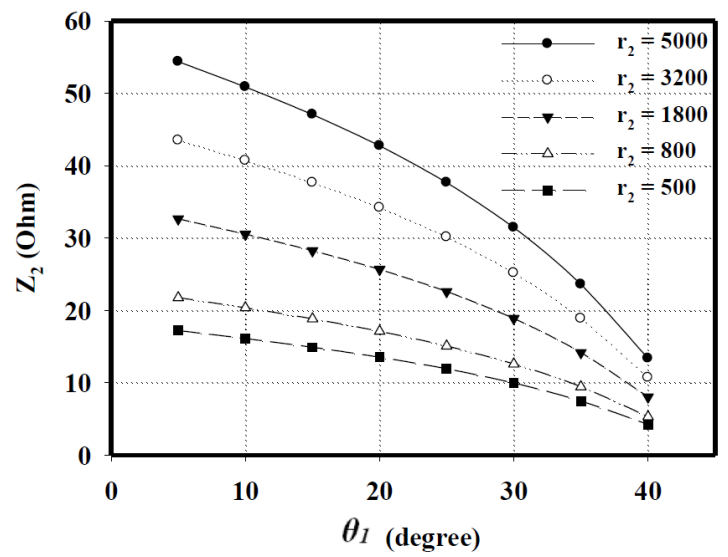

(b)

Fig. 10. Characteristic impedances versus $\theta_{1}$ for the twosection QWLTs with $50 \%$ size reduction, $r_{1}=0.5$ and $\theta_{1}+\theta_{2} \approx 45^{\circ}$. (a) $Z_{1}$, (b) $Z_{2}$.

\begin{tabular}{|c|c|c|c|c|c|c|}
\hline $\begin{array}{c}\text { Multi-section } \\
\text { Ref }\end{array}$ & $\begin{array}{c}\text { Length } \\
\text { (degree) }\end{array}$ & $\begin{array}{c}\text { Bandwidth } \\
\text { (MHz) }\end{array}$ & Arbitrary $\theta$ & Arbitrary $\phi$ & $\begin{array}{c}\text { Number of } \\
\text { Sections }\end{array}$ & $\begin{array}{c}\text { Possibility for } \\
\text { more } \\
\text { reduction }\end{array}$ \\
\hline This paper & 45.10 & 728 & Yes & Yes & 2,3 & Yes \\
\hline$[21]$ & 45.10 & 728 & Yes & No & 2 & Yes \\
\hline$[23]$ & 45.08 & 720 & Yes & Yes & 2 & Yes \\
\hline
\end{tabular}

Tab. 3. Comparison of multi sections. 


\section{Conclusions}

In this paper, compact QWLTs are implemented using the MSTL microstrip technology. For illustration, two- and three-section QWLT characteristics are derived analytically based on the $A B C D$ parameters of QWLTs. In addition, associated voltage and current distributions, SWF, modified SWF and group delay of QWLTs are investigated as well. Simulation results show that an increase in the number of TL sections of QWLT unit cells clearly yields more flexible design QWLT parameters. The prototypes of two- and three-section QWLTs with 50\% physical size reduction are fabricated and tested. It is found that simulated and measured results of $\left|\mathrm{S}_{11}\right|$ for the QWLT prototypes agree reasonably well, without significant bandwidth reduction compared to that of the QWT. In the future, other potential TL structures for the QWLT implementation will be investigated as well for the performance improvement. In addition, QWLTs will be applied to miniaturize other useful microwave devices such as broadband multi-section transformers, power dividers, filters and antennas.

\section{Acknowledgments}

This work has been supported by Petchra Pra Jom Klao Doctoral Scholarship from King Mongkut's University of Technology Thonburi Grant No. 22/2557 and the scholarships from the Thailand Research Fund under the TRF Senior Research Scholar Program and the Royal Golden Jubilee Ph.D. Program with the contract numbers RTA6080008 and PHD/093/2557, respectively. The authors would like to thank the Wireless Communication Laboratory at King Mongkut's University of Technology North Bangkok for their equipment and the CST MWS software. The authors also acknowledge Asian University for the Agilent Genesys EDA software.

\section{References}

[1] ZHU, L. Guided-wave characteristics of periodic coplanar waveguides with inductive loading unit-length transmission parameters. IEEE Transactions on Microwave Theory and Techniques, 2003, vol. 51, no. 10, p. 2133-2138. DOI: 10.1109/TMTT.2003.817435

[2] MIRZAVAND, R., HONARI, M. M., ABDIPOUR, A., MORADI, G. Compact microstrip Wilkinson power dividers with harmonic suppression and arbitrary power division ratios. IEEE Transactions on Microwave Theory and Techniques, 2013, vol. 61, no. 1, p. 61 to 68. DOI: 10.1109/TMTT.2012.2226054

[3] PARK, J. H., LEE, Y. Improved capacitive loading method for miniaturization of $0 \mathrm{~dB}$ forward-wave directional couplers. IEEE Microwave Wireless Components Letters, 2011, vol. 21, no. 4, p. 191-193. DOI: 10.1109/LMWC.2011.2109056

[4] KUO, T. N., LIN, Y. S., WANG, C. H., CHEN, C. H. A compact LTCC branch-line coupler using modified-T equivalent-circuit model for transmission line. IEEE Microwave Wireless
Components Letters, 2006, vol. 16, no. 2, p. 90-92. DOI: 10.1109/LMWC.2005.863194

[5] ZHANG, X. Y., DIN, X., KAO, H. L., WEI, B-H., CAI, Z. Y., XUE, Q. Compact LTCC bandpass filter with wide stopband using discriminating coupling. IEEE Transactions on Components, Packaging, and Manufacturing Technology, 2014, vol. 4, no. 4, p. 656-663. DOI: 10.1109/TCPMT.2013.2297522

[6] LAI, A., ITOH, T., CALOZ, C. Composite right/left-handed transmission line metamaterials. IEEE Microwave Magazine, 2004, vol. 5, no. 3, p. 34-50. DOI: 10.1109/MMW.2004.1337766

[7] CALOZ, C., ITOH, T. Transmission line approach of left-handed (LH) materials and microstrip implementation of an artificial $\mathrm{LH}$ transmission line. IEEE Transactions on Antennas and Propagation, 2004, vol. 52, no. 5, p. 1159-1166. DOI: 10.1109/TAP.2004.827249

[8] FOUDA, A. E., SAFWAT, A. M. E., EL-HENNAWY, H. On the applications of the coupled-line composite right/left-handed unit cell. IEEE Transactions on Microwave Theory and Techniques, 2010, vol. 58, no. 6, p. 1584-1591. DOI: 10.1109/TMTT.2010.2049162

[9] KARPUZ, C. Bandstop characteristics of a triangular microstrip slotted patch as an electromagnetic bandgap (EBG). Microwave and Optical Technology Letters, 2003, vol. 36, no. 3, p. 149-150. DOI: $10.1002 / \operatorname{mop} .10704$

[10] CAKIR, G., SEVGI, L. A design of novel microstrip electromagnetic bandgap (EBG) structure. Microwave and Optical Technology Letters, 2005, vol. 46, no. 4, p. 399-401. DOI: 10.1002/mop.20999

[11] ZHOU, C., YANG, H. Y. D. Design considerations of miniaturized least dispersive periodic slow-wave structures. IEEE Transactions on Microwave Theory and Techniques, 2008, vol. 56, no. 2, p. 467-474. DOI: 10.1109/TMTT.2007.914633

[12] DESLANDES, D., WU, K. Integrated microstrip and rectangular waveguide in planar form. IEEE Microwave Wireless Components Letters, 2001, vol. 11, no. 2, p. 68-70. DOI: 10.1109/7260.914305

[13] BOZZI, M., WINKLER, S. A., WU, K. Broadband and compact ridge substrate integrated waveguides. IET Microwaves, Antennas \& Propagation, 2010, vol. 4, no. 11, p. 1965-1973. DOI: 10.1049/iet-map.2009.0529

[14] NIEMBRO-MARTÍN, A., NASSERDdINE, V., PISTONO, E., ISSA, H., FRANC, A., VOUNG, T., FERRARI, P. Slow-wave substrate integrated waveguide. IEEE Transactions on Microwave Theory and Techniques, 2014, vol. 62, no. 8, p. 1625-1633. DOI: 10.1109/TMTT.2014.2328974

[15] JIN, H., WANG, K., GUO, J., DING, S., WU, K. Slow-wave effect of substrate integrated waveguide patterned with microstrip polyline. IEEE Transactions on Microwave Theory and Techniques, 2016, vol. 64, no. 6, p. 1717-1726. DOI: 10.1109/TMTT.2016.2559479

[16] XUE, Q., SHUM, K. M., CHAN, C. H. Novel oscillator incorporating a compact microstrip resonant cell. IEEE Microwave Wireless Components Letters, 2001, vol. 11, no. 5, p. 202-204. DOI: $10.1109 / 7260.923028$

[17] KURGAN, P., FILIPCEWICZ, J., KITLINSKI, M. Development of a compact microstrip resonant cell aimed at efficient microwave component size reduction. IET Microwaves, Antennas \& Propagation, 2012, vol. 6, no. 12, p. 1291-1298. DOI: 10.1049/iet-map.2012.0192

[18] KOZIEL, S., BEKASIEWICZ, A. Rapid simulation-driven multiobjective design optimization of decomposable compact microwave passives. IEEE Transactions on Microwave Theory and Techniques, 2016, vol. 64, no. 8, p. 2454-2461. DOI: 10.1109/TMTT.2016.2583427 
[19] MCGINN, V. P., MORAN, W. P. Physically short linear impedance transformers. Microwave and Optical Technology Letters, 1988, vol. 1, no. 7, p. 249-252. DOI: 10.1002/mop.4650010708

[20] LIM., T., LEE, S., LEE, Y. Improved method of reactive loading for miniaturisation of transmission lines with minimal degradation in performance. IET Microwaves, Antennas \& Propagation, 2015, vol. 9, no. 9, p. 905-912. DOI: 10.1049/iet-map.2014.0547

[21] CHEN, G., HAMID, M. Multi-section transmission line transformers of arbitrary length. In Symposium of Antenna Technology and Applied Electromagnetics. 1986, p. 1-9. DOI: 10.1109/ANTEM.1986.7856352

[22] AHN, H.-R. Modified asymmetric impedance transformers (MCCTs and MCVTs) and their application to impedancetransforming three-port 3-dB power dividers. IEEE Transactions on Microwave Theory and Techniques, 2011, vol. 59, no. 12 p. 3312-3321. DOI: 10.1109/TMTT.2011.2171708

[23] AHN, H.-R. Compact CVT-/CCT-unequal power dividers for high power-division ratios and design methods for arbitrary phase differences. IEEE Transactions on Microwave Theory and Techniques, 2014, vol. 62, no. 12, p. 2954-2964. DOI: 10.1109/TMTT.2014.2362131

[24] AHN, H.-R., WOLFF, I. General design equations of three-port power dividers, small-sized impedance transformers, and their applications to small-sized three-port 3-dB power dividers. IEEE Transactions on Microwave Theory and Techniques, 2001, vol. 49, no. 7 ,p. 1277-1288. DOI: $10.1109 / 22.932248$

[25] JONGSUEBCHOKE, I., AKKARAEKTHALIN, P., TORRUNGRUENG, D. Theory and design of quarter-wave-like transformers implemented using conjugately characteristic-impedance transmission lines. Microwave and Optical Technology Letters, 2016, vol. 58, no. 11, p. 2614-2619. DOI: 10.1002/mop.30120

[26] TORRUNGRUENG, D. Meta-Smith Charts and Their Potential Applications. La Vergne, TN Morgan \& Claypool, 2010. ISBN-10: 1608455807

[27] WORASAWATE, D., TORRUNGRUENG, D. Analysis of a multi-section impedance transformer using an equivalent CCITL model. In Proceeding of the 2006 ECTI International Conference. Ubon Ratchathani (Thailand), May 2006, p. 111-114.

[28] LIMSAENGRUCHI, S., SILAPUNT, R., TORRUNGRUENG, D. Passband and stopband characteristics on two-section microstrip CCITLs. In Proceeding of the ITC-CSCC 2012. Sapporo (Japan), July 2012

[29] POZAR, D. M. Microwave Engineering. $3^{\text {rd }}$ ed. John Wiley\&Sons, 2004. ISBN: 9788126510498

[30] Agilent Genesys EDA software 2008.07, Agilent Technologies Inc., USA, 2008

[31] CST microwave studio, htttp//www.cst.com

\section{About the Authors ...}

Thanatcha SATITCHANTRAKUL received her B.Eng. and M.Eng. from King Mongkut's University of Technology Thonburi in 2010 and 2014, where she is currently pursuing the Ph.D. degree. Her research interests include antenna applications, transmission line and microwave circuit.

Nonchanutt CHUDPOOTI received the first-class honors B.Sc. degree from the King Mongkut's University of Technology North Bangkok in 2012, where he is currently pursuing the Ph.D. degree. His main research focuses on the application in microwave microfluidic sensors, millimeter-wave substrate integrated circuit applications and Substrate Integrated Waveguide (SIW) applications.

Prayoot AKKARAEKTHALIN received the B.Eng. and M.Eng. degrees in Electrical Engineering from King Mongkut's University of Technology North Bangkok, Thailand, in 1986 and 1990, respectively, and the Ph.D. degree from the University of Delaware, Newark, USA, in 1998. From 1986 to 1988 , he worked in the Microtek Laboratory, Thailand. In 1988, he joined the Department of Electrical Engineering, KMUTNB. His current research interests include passive and active microwave circuits, wideband and multiband antennas, and telecommunication systems. He was the Chairman for the IEEE MTT/AP/ED Thailand Joint Chapter during 2007 and 2008, and the president for ECTI Association, Thailand from 2014 to 2015. He is now working on the Senior Research Scholar Project for Thailand Research Fund (2015-2017).

Rardchawadee SILAPUNT (corresponding author) received the B.E. degree in Electrical Engineering from Chulalongkorn University, Thailand, in 1996, and the M.S. and Ph.D. degrees in Electrical and Computer Engineering from the University of Wisconsin-Madison, USA, in 1998 and 2004, respectively. In 2004, she joined the Department of Electronic and Telecommunication Engineering, King Mongkut's University of Technology Thonburi, Thailand, as a lecturer. Her current research interests include transmission lines and applications, microwave devices, photonics, and plasmonics. Since the beginning of her career, she has received several research grants from government funding agencies and private sectors.

Danai TORRUNGRUENG received his B.Eng. degree in Electrical Engineering from Chulalongkorn University, Bangkok, Thailand, in 1993. He obtained his M.S. and Ph.D. degrees in Electrical Engineering from The Ohio State University in 1996 and 2000, respectively. Prior to joining Asian University, he worked as a senior engineer in the USA, involved in research and development of the urban propagation modeling project. At present, he is a full professor in the Electrical and Electronic Engineering Department, Faculty of Engineering and Technology, Asian University, Thailand. His research interests are in the areas of fast computational electromagnetics, rough surface scattering, propagation modeling, electromagnetic wave theory, microwave theory and techniques, antennas and sensors. 